\title{
The Roles of Instructional Practices and Motivation in Writing Performance
}

\author{
SHUI-FONG LAM \\ YIN-KUM LAW \\ The University of Hong Kong
}

\begin{abstract}
The authors investigated what and how instructional practices are related to students' motivation and performance in writing. The participants were 6 teacher interns and their $(N=209)$ secondary-school students in Hong Kong. In a 3session instruction unit, the teacher interns taught their students how to write an expository essay. The students completed the essay and then a questionnaire to report their motivation in the task and their perception of the instruction. Results of structural equation modeling showed that students' motivation mediated the effects of instructional practices on writing performance. The authors found that when the teachers adopted more motivating teaching strategies, the students were more motivated. When the students were more motivated, they, in turn, had better performance in writing.
\end{abstract}

Key words: instructional practices, motivation, structural equation modeling, teacher education, writing performance

WRITING IS AN activity that is as much emotional as cognitive. Affective factors influence all phases of the writing process (McLeod, 1987). A strong need exists for researchers and educators to explore the affective factors that contribute to students' writing performance. Motivation, with its conspicuous influences, is important among those affective factors. As Bruning and Horn (2000) argued, writing successfully is a complex and effortful activity that requires systematic attention to motivational conditions. Students need to tap the motivational resources within themselves and the support that is available in the instructional environment. In recent years, there has been a proliferation of research on writing

Address correspondence to: Shui-Fong Lam, The Department of Psychology, The University of Hong Kong, Pokfulam Road, Hong Kong, China. E-mail: lamsf@ $h k u s u b . h k u . h k$ 
processes in schools and the motivational factors associated with them. García and de Caso (2004) attributed this recent rise in interest to an increased educational focus on writing throughout the curriculum (Elbow, 2000; Gregg \& Mather, 2002; Wong, 1996). Researchers and educators are well aware that writing ability contributes substantially to general academic success and that it is important to explore factors that affect achievement motivation in this specific domain. In this study, we explored what and how instructional practices are associated with students' motivation and performance in writing.

Researchers and educators have observed consistently that students are motivated in literacy when instruction motivates their literacy behaviors (Bogner, Raphael, \& Pressley, 2002). This observation, however, cannot contribute to our knowledge or guide our practices unless we are able to identify the instructional strategies that motivate students to write. To achieve this task, we turn to the literature of motivation in general, as well as the literature on motivation that is focused on writing.

Lam, Pak, and Ma (2002) identified six components of instructional contexts that are most relevant to students' motivation: challenge, real-life significance, curiosity, autonomy, recognition, and evaluation. Those components constitute instructional practices that are motivating to learning in general. Although they are components of generic motivating practices in instruction, they can also capture the essence of the teaching that specifically develops students' motivation to write (Bruning \& Horn, 2000).

\section{Challenge}

Students are most motivated when they expect that they can successfully complete a writing task that they value. According to expectancy $x$ value theory, the amount of effort students invest is a product of their expectation of success and the values of the reward (Feather, 1969). Students will not invest effort in an extremely difficult task that they have little chance to complete successfully, no matter how attractive the reward may be. Nor will they invest effort in a task that can be completed easily, because an easy task has little value, as it does not contribute to feelings of pride and satisfaction (Atkinson, 1964).

A task that is challenging yet achievable is motivating because it enhances students' perceived value and expectancy of success. The concept of expectancy is intertwined with that of self-efficacy. Students with high self-efficacy believe that they are capable of performing the course of action with success (Bandura, 1977). Although self-efficacy refers to a personal quality and expectancy refers to a belief about a specific event, both are important determinants of whether students will expend effort on a task. Previous studies have shown a consistent relation between self-efficacy and writing performance (Pajares, 2003; Pajares \& Johnson, 1996; Pajares, Miller, \& Johnson, 1999; Pajares \& Valiante, 1997; 
Shell, Colvin, \& Bruning, 1995; Shell, Murphy, \& Bruning, 1989). Writers with high self-efficacy usually have lower anxiety, greater persistence, and higher toleration for frustration in writing tasks.

Students' self-efficacy is most strongly influenced by mastery experiences (Bandura, 1977). Successful learning experiences that are challenging, and yet can be accomplished, are important sources of self-efficacy. Walker (2003) pointed out that "the most observable aspects of successful experiences that influence self-efficacy are when students persist at a task and expend effort in order to produce success" (p. 175). To ensure mastery experiences in writing, teachers need to provide their students with challenging but achievable tasks. Teachers also need to provide scaffolding in the process so that their students can move progressively from easy to more difficult tasks.

\section{Real-Life Significance}

Bruning and Horn (2000) were critical that school writing often takes place under artificial conditions. They observe that writing tasks such as abstracting chapters and books, completing essay exams, and writing term papers are largely of the teacher's making. Oftentimes, teachers do not set those writing activities within larger social or communication frames that can arouse interest and create a sense of writing's relevance. They are only assignments that are submitted to, read, and graded by the teacher and therefore are without real purposes such as persuasion, description, and expressing the writer's thoughts and feelings. Bruning and Horn argued that having genuine reasons for writing is motivating. The ideas they advocate are supported by many studies in motivation and writing (Cleary, 1991; Newby, 1991; Turner, 1995). For example, in a study of the motivational strategies of elementary school teachers, Newby found a significant positive correlation between relevance strategies and students' on-task behaviors. On the basis of the results, Newby suggested that when teachers relate the writing activity to the students' interests, future activities, or past experiences, they help their students to answer such questions as "Why do I have to write this?" and "What is the value of writing this?" Students are likely to become motivated if they know the answers to these questions.

\section{Curiosity}

Another instructional practice that can increase the value attached to the successful completion of a task is to evoke students' curiosity about the task. Certain conditions in instructional contexts can be sources of interest to students. These conditions usually involve novelty, surprise, and uncertainty (Ainley, Hidi, $\&$ Berndorff, 2002; Hidi \& Harackiewicz, 2000). Humans are intrinsically motivated to remove ambiguity and confusion related to cognitive conflict or disso- 
nance (Bergin, 1999). Many researchers (e.g., Langer, 1987; Needels \& Knapp, 1994) have argued that good writing tasks should pose an intellectual challenge to students. Effective teachers know how to guide their students to approach writing as a problem-solving process. Applebee, Langer, and Mullis (1987) found that students' writing competence was associated positively with instruction that focused on a problem-solving process. In a meta-analysis, Hillocks (1984) also found that instruction emphasizing inquiry had a strong positive effect on the quality of students' writing. In view of those evidences, the instructional strategies that can stimulate students' curiosity in problem solving are also expected to increase their motivation in writing.

\section{Autonomy}

The motivational effects of autonomy have been well documented in the literature. Researchers consistently show that intrinsic motivation is greater among individuals who are given the opportunity to make choices and to have control of their own outcomes (Condry, 1977; Deci, 1975, 1981; Lepper \& Malone, 1987; Zuckerman, Porac, Lathin, Smith, \& Deci, 1978). According to R. M. Ryan and Deci (2000), the leading proponents of self-determination theory, the need for autonomy is one of the fundamental and universal needs of people. They argue that satisfaction of this basic psychological need provides the nutriments for motivation. Therefore, social environments can facilitate motivation by supporting people's needs for autonomy. Researchers have shown that children develop stronger intrinsic motivation when parents and teachers are less controlling and more supportive of their autonomy in choosing and initiating activities (Deci, Hodges, Pierson, \& Tomasone, 1992; Grolnick, Ryan, \& Deci, 1991; Rosenholtz \& Simpson, 1984; Skinner \& Belmont, 1993). To motivate students to write, teachers can allow more autonomy in the writing processes, such as giving freedom in the choice of content, styles, and approaches. As Bruning and Horn (2000) pointed out, gaining and maintaining control of a writing task is critical to motivation.

\section{Recognition}

Weiner $(1979,1986)$ postulated in the attribution theory that one can explain differences in student effort expenditure by differences in how they describe their success and failure. Effort is an internal, unstable, and controllable factor. When students attribute their success and failure to effort, they are more likely to invest effort in future tasks. Muller and Dweck (1998) found that children who were praised for effort were more motivated than were children who were praised for intelligence. Their findings are related intricately to achievement goal theories (Dweck, 1986; Nicholls, 1984). Students with performance goals focus on gaining positive evaluations from others. They are motivated to attempt difficult tasks 
if they are confident but withdraw when they lack confidence or are faced with failure. In contrast, students with learning goals focus on gaining new skills and knowledge. They are not thwarted by failure because they see failure as a cue to change their strategy and increase their effort. Praise for their intelligence links performance to an esteem-relevant attribute, encouraging students to perform well and to adopt a performance goal instead of a learning goal.

The findings of Muller and Dweck (1998) were supported by many classroombased studies in which learning motivation in general (Ames \& Archer, 1988; Nolen, 1988; A. M. Ryan, Gheen, \& Midgley, 1998) and motivation in writing specifically were investigated (Schunk \& Swartz, 1993). In recent years, however, some researchers (e.g., Harackiewicz, Barron, Pintrich, Elliot, \& Thrash, 2002) have argued that performance goals may not be that detrimental. According to those researchers, only performance avoidance goals, a subtype of performance goals, are associated with maladaptive motivation, whereas performance approach goals, the other subtype of performance goals, can be associated with adaptive motivation. Despite the controversy over performance goals, most researchers (e.g., Harackiewicz, et al., 2002; Midgely, Kaplan, \& Middleton, 2001) agree that learning goals promote optimal motivation. To help students adopt learning goals, teachers may give recognition to students who have made an effort and achieved self-improvement.

\section{Evaluation}

Normative evaluation and social comparison can compel students to give up learning goals for performance goals (Lam, Yim, Law, \& Cheung, 2004; Rawsthorne \& Elliot, 1999). When teachers adopt normative evaluation, students are more concerned with gaining a positive evaluation relative to others (performance goals) than with gaining new skills and knowledge (learning goals). In addition to social comparison, some other practices of evaluation also promote performance goals in students. When evaluation is conducted with no feedback other than a grade or mark, students are led to focus on performance instead of on ways to improve. In a study of different kinds of feedback given after evaluation, Butler (1987) found that individual comments yielded higher learning goals and lower performance goals. In contrast, attributions related to performance goals were highest after receipt of grades and praise without individual comments.

The most useful feedback on writing tends to involve specific knowledge on how to achieve one's writing goals (Bruning \& Horn, 2000). Students usually respond favorably to specific and explicit suggestions to improve their writing (Straub, 1996, 1997). Specific feedback on improvement is actually a powerful source for developing self-efficacy in reading and writing (Walker, 2003). Gersten and Baker (2001) did a meta-analysis of writing interventions for students with 
learning disabilities. They found that extensive feedback on the quality of writing is an indispensable component of successful interventions.

Researchers also consistently found that students' writing confidence and competence increased when they were provided with regular feedback on how well they used strategies to make improvement (Graham \& MacArthur, 1988; Graham, MacArthur, Schwartz, \& Page-Voth, 1992; Schunk \& Swartz, 1993). To motivate students to write, teachers can make task-specific comments about students' success and attribute their success to strategies that are learnable through effort (Schunk, 2003). Specific instructional strategies include avoiding social comparisons, emphasizing self-improvement, and giving suggestions on how to improve.

\section{Overview of the Study}

The pedagogical literature provides us with clues that certain instructional practices are motivating and may bring about better student writing performance. However, little research has been done to investigate those instructional practices comprehensively in classrooms. In this field study, composed of empirical data collected from classrooms, we investigated the relationships among those instructional practices, motivation, and writing performance. We expected that instructional practices would be motivating when teachers provided challenging tasks, highlighted real-life relevance, stimulated curiosity, allowed a high level of autonomy, recognized students' effort, and provided useful feedback. We also expected that students would have better writing performance when they were motivated in the writing task. We see that motivation is a mediator between instructional practices and writing performance. In other words, motivating instructional practices increase students' motivation, which, in turn, enhances their writing performance.

\section{Method}

\section{Participants}

The participants were seventh- and eighth-grade students $(N=209)$ from four secondary schools in Hong Kong. All participants were the students of six teacher interns enrolled in a post-graduate certificate program of education, with a major in Chinese Language Teaching, at the University of Hong Kong. The six teacher interns were in their early 20s and had recently obtained their bachelors' degrees. All but one of them were women. We invited them to participate in this study on a voluntary basis. We assured them that their participation would not affect their training and that their identities would remain anonymous. Through their assistance, we recruited their students for this study. The mean age of these students was 13.29 years. About $31 \%$ of them were seventh graders and $69 \%$ 
were eighth graders. Fifty-five percent of them were boys. Although their schools might be geographically distant from one another in the territories of Hong Kong, all of them were located in middle-lower social economic status (SES) neighborhoods.

\section{Procedure}

The six teacher interns attended an 8-week internship in these schools in the last semester of their training. Toward the end of their internship, they taught their students how to write expository essays. This instruction unit consisted of three sessions. Each session was 40 min long. The first and second sessions ran consecutively on the same day, and the third session was scheduled a week later. In the first session, the teachers introduced the expository genre of writing to their students. In the second session, they asked their students to write an expository essay independently in class. The teachers collected the essays at the end of the second session, graded the essays after class, and returned them to the students in the third session a week later. Feedback on how to make improvements was given in this third session. According to Hillocks' (1984) classification, the teacher interns' mode of instruction may be described as a mixture of presentational and environmental modes. Presentational mode is the most common and traditional mode of instruction in composition. In this mode, the teacher is the center, and the instruction is characterized by structured lecture and teacher-led discussion. In environmental mode, the teacher plans the activities and selects the materials, but students are given opportunities to interact with each other to generate ideas and learn identifiable writing skills. The instruction in this study was characterized by relatively long lectures by the teacher and brief, small group discussions among the students (e.g., students helped one another to identify ideas for the expository essay). Therefore, this approach constitutes a mixture of presentation and environmental modes.

At the end of the entire instruction unit, a research assistant asked the students to complete a questionnaire after the teacher intern had left the classroom. The questionnaire was presented in Chinese. With it, we tapped their perceptions and evaluations of the learning experience and of their teachers' instructional practices in those three sessions.

\section{Measures}

Instructional practices. In the questionnaire, we adapted 18 items from the Motivating Instructional Contexts Inventory (MICI; Lam et al., 2002). The MICI consists of six subscales, namely, challenge, real-life significance, curiosity, autonomy, recognition, and evaluation. They respectively measure the extent to which students perceive that their teachers provide them with challenging tasks, 
ensure real-life significance in their learning activities, arouse their curiosity, grant them autonomy, recognize their effort, and provide useful feedback for their improvement. The MICI is composed of 24 items, with 4 items in each subscale. Because the items tap generic motivating practices in instruction, we reduced them to 18 items and reworded them so that they were targeted specifically at the three-session instruction unit on expository essay. We included 3 items in each subscale (see Appendix for the English translation of those items). In the questionnaire, we asked the students to indicate how much they agreed that the 18 statements accurately described the practices of their teachers in the writing lesson. For example, to the statement "Our teacher let us write the essay freely with our ideas," the students indicated the extent to which they agreed that this described their teacher's instructional practices on a 6-point Likert scale with 1 for strongly disagree and 6 for strongly agree. The Cronbach's $\alpha$ of the six subscales ranged from .64-.79 for this sample. The Cronbach's $\alpha$ of the total scale with 18 items was .94 (95\% confidence interval $[C]=93-95)$. We used the average score of the items as an index of the students' perception of their teachers' instructional practices. High scores indicated that the students agreed that their teachers adopted instructional practices that were motivating. Low scores indicated otherwise.

Students' self-reported motivation. The questionnaire completed by the students at the end of the instruction unit also included a scale that measured their motivation in writing the expository essay. We adapted this scale from the motivation scale of Elliott and Church (1997). It consisted of five statements, such as "I enjoyed writing this essay very much." We asked the students to indicate their agreement to these statements on a 6-point Likert scale: 1 for strongly disagree and 6 for strongly agree. Because the original scale was in English, we translated the items into Chinese following Brislin's (1970) back-translation procedure. The Cronbach's $\alpha$ of this scale was .88 (95\% CI $=85-90)$ for this sample. We used the average score for the five statements as the index of students' self-reported motivation in the learning experience: the higher the score, the more the students were motivated to write.

Writing performance. In the second session of the instruction unit, the teachers asked the students to write an expository essay of 300 words in Chinese. The teachers requested that the students introduce two tourist attractions in Hong Kong to tourists from Mainland China. Two research assistants, who were blind to our purpose in this study, independently graded the student's essays. Both raters were senior students with majors in Chinese Language Education. Their ratings were made on a 100-point scale that is commonly used in Hong Kong classrooms. The correlation of their grading was $.89, p<.001$. There was no significant difference between their scores, $t(198)=.51, p>.05$, Cohen's $d=.04$. 
The average of their scores for each student was used as the indicator of the student's performance in writing.

Baseline performance. At the beginning of their internship, the six teacher interns asked their students to write a 200 -word essay to introduce their schools. The scores on this essay served as a baseline of the students' performance in writing. A research assistant, who did not know the purpose of this study, graded the essays written before the instruction unit. The rater was again a senior student majoring in Chinese Language Education and the ratings were made on a 100-point scale. To check the reliability of her grading, one-third of the essays were graded by another rater. The correlation of their grading was $.92, p<.001$. The difference between their scores was not significant statistically, $t(60)=-1.15, p>.05$, Cohen's $d=-.15$.

\section{Results}

\section{Correlation Among the Variables}

In Table 1, we present the Pearson zero-order correlation coefficients among the six subscales of motivating instructional practices, motivation, baseline performance, and writing performance. A high correlation among the six subscales of motivating instructional practices indicated that those subscales tapped different aspects of the same construct. We averaged the scores of these subscales and obtained a score of motivating instructional practices. We observed that this score had a statistically significant correlation with students' motivation and writing performance. However, it is noteworthy that baseline performance was not associated with any of the other variables. Because it had little association with the other variables, we did not use it as covariate in further analyses.

\section{Structural Equation Modeling}

We used LISREL 8.3 (Jöreskog \& Sörbom, 1999) to test a model in which motivation mediated the effect of instructional practices on writing performance. The model contained one exogenous variable, namely, instructional practices, and two endogenous variables, which were students' motivation and writing performance. We measured the latent construct of instructional practices with the following six subscales: challenge, real-life significance, curiosity, autonomy, recognition, and evaluation. We measured the construct of motivation by using five items adapted from the motivation scale developed by Elliott and Church (1997). We measured the students' writing performance by using the marks given by the two raters. Because the two raters were highly consistent in their grading $(r=.89, p<.001)$, we assumed that there was very little measurement error for writing performance. To avoid negative error variance because of extremely high 


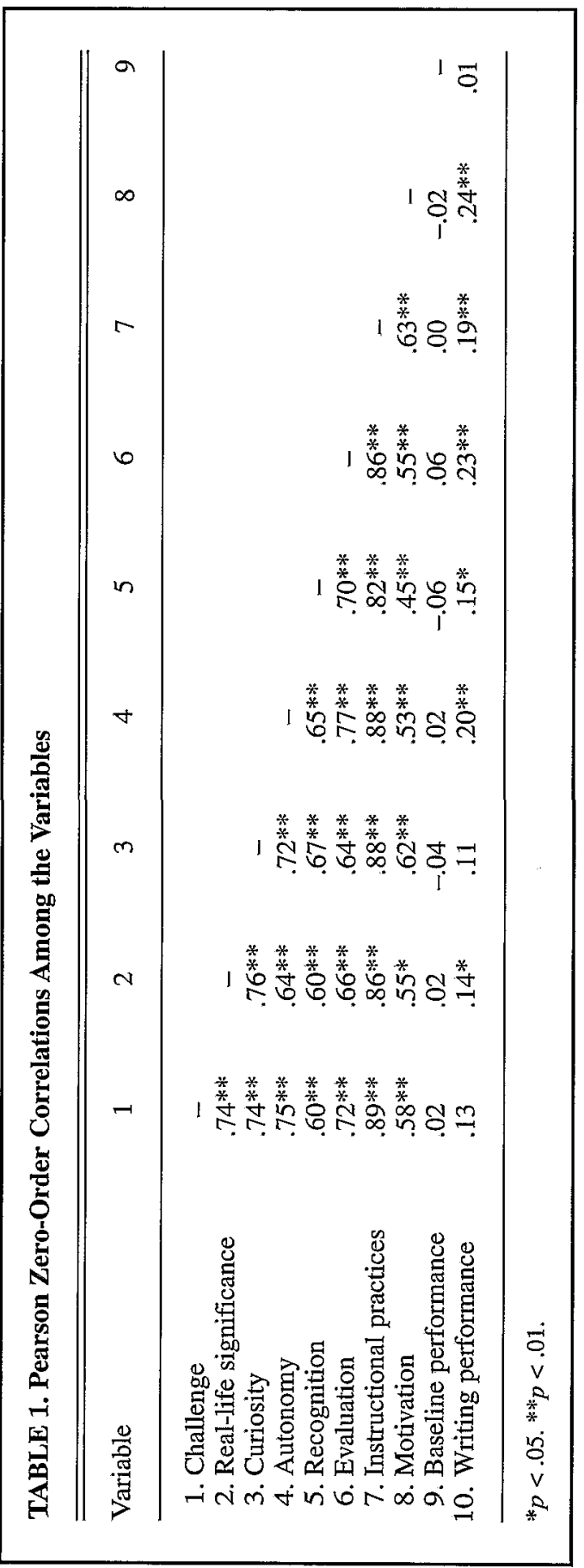


correlation between Raters 1 and 2, we set the error term of rater one to zero in the model.

Among the 209 participants, 19 participants did not have complete data and we excluded them from the analyses as a result of list-wise deletion. The results of LISREL with 190 participants showed that the chi-square value was significant for the overall model, $\chi^{2}(63, N=190)=175.31, p<.001$. As an absolute fit index, the chi-square assesses the discrepancy between the sample covariance matrix and the implied covariance matrix on the basis of the hypothesized model. A nonsignificant chi-square suggests that the model may be a reasonable representation of the data. However, the assessment of fit using the chi-square test is confounded by sample size (Fan, Thompson, \& Wang, 1999; Hu \& Bentler, 1995). When the sample size is large, a trivial difference between the sample covariance matrix and the reproduced covariance may be found significant. Therefore, some researchers (e.g., Finney, Pieper, \& Barron, 2004) have recommended that chisquare be complemented with additional fit indexes.

Relative-fit indexes and residual-based indexes are two types of additional fit indexes used widely to complement chi-square. Relative-fit indexes include comparative fit index (CFI), nonnormed fit index (NNFI), and incremental fit index (IFI). Those indexes measure the relative improvement in fit by comparing a hypothesized model with a baseline model. The baseline model is an independence model in which all variables are expected to be uncorrelated. Those indexes range from zero to one, with larger values indicating a better fit. They should be at least larger than .90 for reasonable goodness of fit. In the present study, CFI $=$ $.92, \mathrm{NNFI}=.92$, and $\mathrm{IFI}=.92$. All those relative indexes suggested a reasonable fit between the data and the hypothesized model.

Other than relative-fit indexes, residual-based indexes can also be used. Standardized root mean square (SRMR) measures the average value across all standardized residuals between the elements of the observed and implied covariance matrices. Root mean square error of approximation (RMSEA) assesses absence of fit because of model misspecification and provides a measure of discrepancy per degree of freedom (Browne \& Cudeck, 1993). Both SRMR and RMSEA range from zero to one, with smaller values indicating better model fit. A value of .08 or less for $S R M R$ and a value of .06 or less for RMSEA indicate adequate fit $(\mathrm{Hu}$ \& Bentler, 1998). In this study, $S R M R=.051$, whereas $R M S E A=.097(90 \% \mathrm{CI}-$ $.08 ; .11$ ). Given that this is a very stringent model in which the correlations among all measurement errors were not set free, those fit statistics indexes showed that the model fit the data fairly well.

The correlations among the latent constructs were .70 for instructional practices and motivation, .20 for instructional practices and writing performance, and .25 for motivation and writing performance. The constructs of instructional practices correlated highly with that of motivation but slightly with that of writing performance. The correlation between the constructs of motivation and writing performance was 
also slight. The correlations among the latent constructs were similar to the Pearson zero-order correlations among the average item sets per construct (see Table 1).

We present the structural and measurement coefficients from the completely standardized solution under maximum likelihood in Figure 1. The path between instructional practices and students' motivation was significant $(\beta=.70, p<.001)$, suggesting that students reported more motivation in the writing task when they perceived that their teachers provided them with challenging tasks, ensured reallife significance in their learning activities, stimulated their curiosity, granted them autonomy, acknowledged their effort, and gave them useful feedback for improvement. The path between motivation and writing performance was also significant statistically $(\beta=.22, p<.05$ ), suggesting that the more the students reported that they were motivated in the writing task, the better the score they would receive from the two raters. However, the path between instructional practices and writing performance was not significant statistically $(\beta=.04, p>.05)$. No direct effect of instructional practices on writing performance was evident. Nevertheless, we did see indirect effect from instructional practices on writing performance through motivation $(\beta=.15, p<.05)$. Because total effect is the sum of direct effect and indirect effect, the total effect of instructional practices on writing performance was $.19(.15+.04)$. This is exactly the Pearson zero-order correlation between instructional practices and writing performance (see Table 1).

\section{Discussion}

In this study, we investigated the relationships among instructional practices, motivation, and writing performance. The results show a mediation model in which students' motivation mediated the effects of instructional practices on writing performance. Those findings add to the existing body of knowledge and help researchers and educators identify what and how instructional practices are associated with students' motivation and writing performance. In the existing literature, little research has been done to examine motivating instructional practices comprehensively and to investigate how they relate to students' motivation and performance in writing. In the past, some researchers have examined how one or two specific teaching strategies affected students' motivation and writing performance. For example, Schunk and Swartz (1993) focused on the effect of feedback. However, there is a dearth of research that examines the comprehensive array of instructional strategies that motivate students to write. Some researchers did investigate the effects of more comprehensive instructional strategies on motivation, but they did not look into the actual performance of students. For example, Bogner et al. (2002) tried to identify the instructional practices that would motivate literacy engagement. However, they did not examine the students' writing performance. A few researchers did look into students' writing performance. For example, Pajares and Johnson (1996) examined how self-efficacy beliefs were 


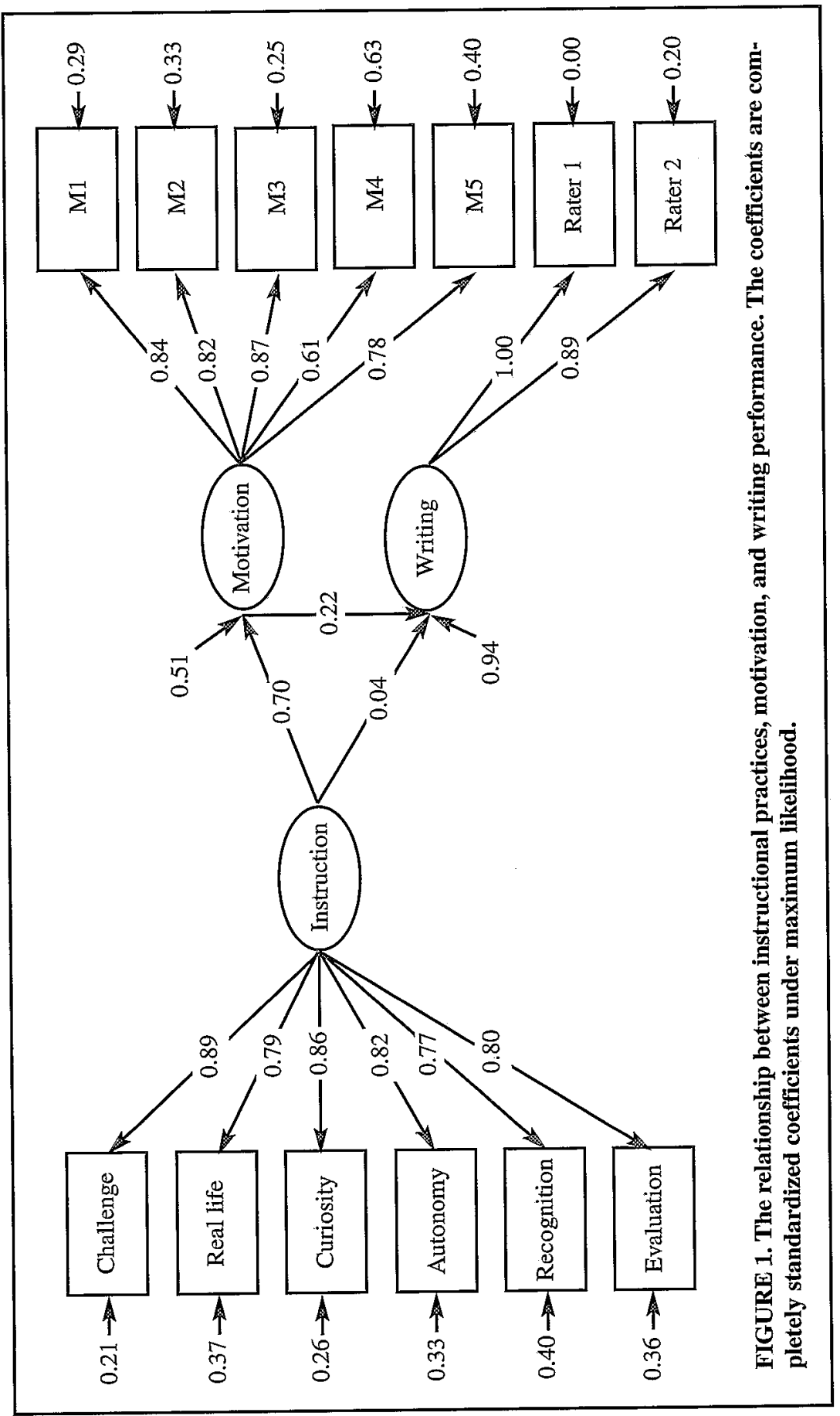


related to writing performance. However, they did not examine instructional practices. With this study, we have made a unique contribution to the existing body of knowledge about what and how instructional practices are related to students' motivation and performance in writing by including instructional practices, motivation, and writing performance in the purview of our inquiry.

Through our results, we show that students will be motivated when their teachers provide them with challenging tasks, ensure real-life significance in their learning activities, stimulate their curiosity, grant them autonomy, recognize their effort, and give them useful feedback for improvement. Furthermore, we show that when students are motivated, they will have better writing performance. This information is helpful to educators who are eager to enhance student motivation in writing.

Although the instructional practices examined in our study were restricted to the three 40-min sessions, we were able to observe their effects on students' motivation and writing performance. The effects of such a brief intervention may have resulted from to the level of specificity involved in the current study. Instead of using the original items of the MICI (Lam et al., 2002) that measure motivating practices in general, we used the modified items that targeted specifically the three-session instruction unit on expository essay: We also calibrated the measurement of the two dependent variables, students' motivation and writing performance, to capture specifically their motivation and performance in the expository essay that they learned and finished in the three-session instruction unit. If the dependent variables were motivation and performance in general, then we would not expect that such a brief intervention would have significant effects.

The results of our study are informative and useful to teacher education. In her review of the problems in teacher education since the 1980s, Cochran-Smith (2004) criticized teacher education for its over-emphasis on teachers' knowledge, skills, and beliefs but lack of adequate attention to student's learning. She advocated establishing links among what teachers know, believe, and do, how they develop professional practice in classrooms, and what their students learn that can be demonstrated on tests and other measures. Our study is a response to a need to investigate how teachers' behaviors in classrooms are related to the students' learning outcomes. The results are informative to teacher educators and teacher interns who are concerned with instructional practices that can bring about higher motivation and better student performance.

However, the fact that the participants were teacher interns and their students may be a limitation of the current research. We collected the data during the 8week internship, and the teacher interns were very conscious of their performance. Although we assured them that the data collected had nothing to do with their evaluation, they probably prepared heavily for the instruction unit that was being studied. As teacher interns who were concerned about their performance appraisal, their behaviors in the classrooms may have differed from those of reg- 
ular classroom teachers who do not teach under such pressure. Furthermore, the students might have responded differently to the instructional practices of teacher interns than they would have to regular classroom teachers, because they knew that the teacher interns were novice teachers. Therefore, the generalization of the results from this study should be viewed with caution.

The results of structural equation modeling supported a mediation model in which students' motivation mediates the effect of the instructional practices on students' writing performance. Although we used the term effect in the report of the results, it does not indicate any cause and effect relationships among instructional practices, motivation, and writing performance. Our research was a field study in which we collected natural data without experimental manipulation. The data from a correlational study do not imply causal effect. The interpretation of the results of structural equation modeling should be made with this caveat.

The instructional practices we measured in this study were perceptions reported by the students. They were high-inference data that required students to make meaningful interpretations and judgments of their experiences. Those data are different from low-inference data obtained in regard to specific and directly observable behavior in the eyes of a third-party observer. High-inference data from students are not necessarily inferior to low-inference data from observers. They are accurate reflections of the students' subjective representation of the instruction they have experienced. They can be collected with a paper and pencil survey that is administered to a large number of participants with simple instructions and no expensive equipment. Despite these merits, the validity and reliability of the evidence gathered in this study would be strengthened if the students' perception were complemented by the report of a third-party observer.

The six instructional practices described in the MICI are targeted primarily at the development of intrinsic motivation in students. However, students may be highly motivated in an activity even if they are not intrinsically interested in it (Lepper \& Henderlong, 2000). According to self-determination theory (A. M. Ryan \& Deci, 2000), students achieve a high degree of internal self-regulation if they can internalize the value of the activity. Relatedness is important for internalization. Students will internalize the value of learning activities if they have good relationships with their teachers. In recent years, many researchers have found a strong association between interpersonal relationships and learning motivation (e.g., Furrer \& Skinner, 2003; Skinner \& Belmont, 1993; Stipek et al., 1998; Wentzel, 1999). It is worthwhile to include affective support from teachers in future investigation of the relation between instructional practices and student motivation.

The students in this study were nested within six classrooms. We employed a disaggregate approach to analyze the data and treated all students as independent subjects. This approach ignores the fact that they were nested within classrooms and may overestimate the correlation between the dependent and independent variables. Hierarchical linear modeling (HLM; Raudenbush \& Bryk, 2002) is a 
more appropriate type of analysis for multilevel data. However, HLM requires a considerable sample size. To detect cross-level interactions with adequate power, a sample of 30 groups with 30 individuals is required (Bassiri, 1988; Van Der Leeden \& Busing, 1994). Because we had only six classrooms with an average of 35 students, our sample size did not meet the requirements of HLM. One direction for future studies is to obtain a larger sample size from more classrooms.

Despite the aforementioned limitations, this study illuminates the roles of instructional practices and motivation in students' writing performance. With the theoretical framework of the MICI, we identified what instructional practices can motivate students to write better. We provide an easy reference to educators who try to enhance students' motivation and performance in writing. To further investigate the relationships among instructional practices, students' motivation, and writing performance, future studies should be conducted on the basis of the experiences of seasoned teachers rather than on those of teacher interns. Data from third-party observers can be used to strengthen the data obtained from students' reports. A larger sample size, with data from more classrooms will lend itself well to HLM. Last but not least, affective components of instructional practices can be included in the future investigation of students' motivation and learning context.

\section{ACKNOWLEDGMENT}

This research was supported by Grant 10205188/24026/30200/323/01 of the Conference and Research Grant Committee (CRGC) at the University of Hong Kong. The authors are grateful to Gloria Ku, Minerva Lam, Wing-sze Lau, Kathy Lee, Kwan-yu Lee, Annie Shu, and James Wong for their assistance in data collection. They are also grateful to the teacher interns and students who took time to participate in the study.

\section{REFERENCES}

Ainley, M., Hidi, S., \& Berndorff, D. (2002). Interest, learning, and the psychological processes that mediate their relationship. Journal of Educational Psychology, 94, 545-561.

Ames, C., \& Archer, J. (1988). Achievement goals in the classroom: Students' learning strategies and motivation processes. Journal of Educational Psychology, 80, $260-267$.

Applebee, A. N., Langer, J., \& Mullis, I. V. S. (1987). Learning to be literate in America. Princeton, NJ: Educational Testing Service.

Atkinson, J. (1964). An introduction to motivation. Princeton, NJ: Van Nostrand.

Bandura, A. (1977). Self-efficacy: Toward a unifying theory of behavioral change. Psychological Review, 84, 191-215.

Bassiri, D. (1988). Large and small sample properties of maximum likelihood estimates for the hierarchical linear model. Unpublished doctoral thesis, Department of Counseling, Educational Psychology, and Special Education, Michigan State University, East Lansing.

Bergin, D. A. (1999). Influences on classroom interest. Educational Psychologist, 34, 87-98.

Bogner, K., Raphael, L., \& Pressley, M. (2002). How grade 1 teachers motivate literate activity by their students. Scientific Studies of Reading, 6, 135-15. 
Brislin, R. W. (1970). Back translation for cross-cultural research. Journal of Cross-Cultural Psychology, 13, 185-216.

Browne, M. W., \& Cudeck, R. (1993). Alternative ways of assessing model fit. In K. A. Bollen \& J. S. Long (Eds.), Testing structural equation models (pp. 136-162). Newbury Park, CA: Sage.

Bruning, R., \& Horn, C. (2000) Developing motivation to write. Educational Psychologist, 35, $25-37$.

Butler, R. (1987). Task-involving and ego-involving properties of evaluation: Effects of different feedback conditions on motivational perceptions, interest, and performance. Journal of Educational Psychology, 79, 474-482.

Cleary, L. M. (1991). Affect and cognition in the writing processes of eleventh graders. Written Communication, 8, 473-507.

Cochran-Smith, M. (2004). The problem of teacher education. Journal of Teacher Education, 55 , 295-299.

Condry, J. (1977). Enemies of exploration: Self-initiated versus other initiated learning. Journal of Personality and Social Psychology, 35, 459-477.

Deci, E. L. (1975). Intrinsic motivation. New York: Plenum.

Deci, E. L. (1981). The psychology of self-determination. Lexington, MA: Health.

Deci, E. L., Hodges, R, Pierson, L., \& Tomasone, J. (1992). Autonomy and competence as motivational factors in students with learning disabilities and emotional handicaps. Journal of Learning Disabilities, 25, 457-471.

Dweck, C. S. (1986). Motivational processes affecting learning. American Psychologist, 41, 1040-1048.

Elbow, P. (2000). Everyone can write. Essays toward a hopeful theory of writing and teaching writing. New York: Oxford University Press.

Elliott, A. J., \& Church, M. A. (1997). A hierarchical model of approach and achievement. Journal for Personality and Social Psychology, 72, 218-232.

Fan, S., Thompson, B., \& Wang, L. (1999). Effects of sample size, estimation methods, and model specification on structural equation modeling fit indexes. Structural Equation Modeling, 6, 56-83.

Feather, N. T. (1969). Attribution of responsibility and value of success and failure in relation to initial confidence and task performance. Joumal of Personality and Social Psychology, 13, 129-144.

Finney, S. J., Pieper, S., \& Barron, K. (2004). Examining the psychometric properties of the achievement goal questionnaire in a general academic contact. Educational and Psychological Measurement, 64, 365-382.

Furrer, C., \& Skinner, E. (2003). Sense of relatedness as a factor in children's academic engagement and performance. Joumal of Educational Psychology, 95, 148-162.

García, J. N., \& de Caso, A. M. (2004). Effects of a motivational intervention for improving the writing of children with learning disabilities. Learning Disability Quarterly, 27, 141-159.

Gersten, R., \& Baker, S. (2001). Teaching expressive writing to students with learning disabilities: A meta-analysis. Elementary School Journal, 101, 251-272.

Graham, S., \& MacArthur, C. (1988). Improving learning disabled students' skills at composing essays: Self-instructional strategy training. Exceptional Children, 56, 201-214.

Graham, S., MacArthur, C., Schwartz, S., \& Page-Voth, V. (1992). Improving compositions of students with learning disabilities using a strategy involving product and process goal setting. Exceptional Children, 58, 322-334.

Gregg, N., \& Mather, N. (2002). School is fun at recess: Informal analyses of written language for students with learning disabilities. Journal of Leaming Disabilities, 35, 7-22.

Grolnick, W., Ryan, R. M., \& Deci, E. L. (1991). Inner resources for school achievement: Motivational mediators of children's perceptions of their parents. Journal of Educational Psychology, 83, 508-517.

Harackiewicz, J. M., Barron, K. E., Pintrich, P. R., Elliot, A. J., \& Thrash, T. M. (2002). Revision of achievement goal theory: Necessary and illuminating. Joumal of Educational Psychology. 94, 638-645.

Hidi, S., \& Harackiewicz, J. M. (2000). Motivating the academically unmotivated: A critical issue for the 21st century. Review of Educational Research, 70, 151-179.

Hillocks, G. (1984). What works in teaching composition: A meta-analysis of experimental treatment studies. American Journal of Education, 93, 133-170.

Hu, L., \& Bentler, P. M. (1995). Evaluating model fit. In R. H. Hoyle (Ed.), Structural equation modeling: Concepts, issues, and applications (pp. 76-99). Thousand Oaks, CA: Sage. 
Hu, L., \& Bentler, P. M. (1998). Fit indices in covariance structure modeling: Sensitivity to underparameterized model misspecification. Psychological Methods, 3, 424-453.

Jöreskog, K. G., \& Sörbom, D. (1999). LISREL 8.3: User's reference guide. Chicago: Scientific Software.

Lam, S. F., Pak, T. S., \& Ma, W. Y. K. (2002, July). The motivating instructional contexts inventory. Paper presented at the 25th International Congress of Applied Psychology, Singapore.

Lam, S. F., Yim, P. S., Law, J. S. F., \& Cheung, R. W. Y. (2004). The effects of competition on achievement motivation in Chinese classrooms. British Journal of Educational Psychology, 74, 281-296.

Langer, J. (1987). Language, literacy, and culture: Issues of society and schooling. Norwood, NJ: Ablex.

Lepper, M. R., \& Henderlong, J. (2000). Turning "play" into "work" and "work" into "play": 25 years of research on intrinsic versus extrinsic motivation. In C. Sansone \& J. M. Harackiewicz (Eds.), Intrinsic and extrinsic motivation: The search for optimal motivation and performance. (pp. 257-307). San Diego, CA: Academic Press.

Lepper, M. R., \& Malone, T. W. (1987). Intrinsic motivation and instructional effectiveness in computer-based education. In R. E. Snow \& M. J. Farr (Eds.), Aptitude, learning, and instruction: Vol. 3. Cognitive and affective process analysis (pp. 255-286). Hillsdale, NJ: Erlbaum.

McLeod, S. (1987). Some thoughts about feelings: The affective domain and the writing process. College Composition and Communication, 36, 465-471.

Midgley, C., Kaplan, A., \& Middleton, M. (2001). Performance-approach goals: Good for what, for whom, under what circumstances, and at what cost? Journal of Educational Psychology, 93, 77-86.

Muller, C. M., \& Dweck, C. S. (1998). Praise for intelligence can undermine children's motivation and performance. Journal of Personality and Social Psychology, 75, 33-52.

Needels, M. C., \& Knapp, M. S. (1994). Teaching writing to children who are underserved. Journal of Educational Psychology, 86, 339-349.

Newby, T. J. (1991). Classroom motivation: Strategies of first-year teachers. Journal of Educational Psychology, 83, 195-200.

Nicholls, J. G. (1984). Achievement motivation: Conceptions of ability, subjective experience, task choice, and performance. Psychological Review, 91, 328-346.

Nolen, S. B. (1988). Reasons for studying: Motivational orientations and study strategies. Cognition and Instruction, 5, 269-287.

Pajares, F. (2003). Self-efficacy beliefs, motivation, and achievement in writing: A review of the literature. Reading and Writing Quarterly, 19, 139-158.

Pajares, F., \& Johnson, M. J. (1996). Self-efficacy beliefs and the writing performance of entering high school students. Psychology in the Schools, 33, 163-175.

Pajares, F., Miller, M. D., \& Johnson, M. J. (1999). Gender differences in writing self-beliefs of elementary school students. Journal of Educational Psychology, 91, 50-61.

Pajares, F., \& Valiante, G. (1997). The predictive and mediational role of the writing self-efficacy of upper elementary students. Journal of Educational Research, 90, 353-360.

Raudenbush, S., \& Bryk, T. (2002). Hierarchical linear models: Applications and data analysis method. Thousand Oaks, CA: Sage.

Rawsthorne, L. J., \& Elliott, A. J. (1999). Achievement goals and intrinsic motivation: A meta-analytic review. Personality and Social Psychology Review, 3, 326-344.

Rosenholtz, S. J., \& Simpson, C. (1984). Classroom organization and student stratification. Elementary School Journal, 85, 21-37.

Ryan, A. M., Gheen, M. H., \& Midgley, C. (1998). Why do some students avoid asking for help? An examination of the interplay among students' academic efficacy, teachers' social-emotional role, and the classroom goal structure. Journal of Educational Psychology, 89, 329-341.

Ryan, R. M., \& Deci, E. L. (2000). Self-determination theory and the facilitation of intrinsic motivation, social development, and well-being. American Psychologist, 55, 68-78.

Schunk, D. H. (2003). Self-efficacy for reading and writing: Influence of modeling, goal setting and self-evaluation. Reading and Writing Quarterly, 19, 159-172.

Schunk, D. H., \& Swartz, C. W. (1993). Goals and progress feedback: Effects on self-efficacy and writing achievement. Contemporary Educational Psychology, 18, 337-354.

Shell, D. F., Colvin, C., \& Bruning, R. H. (1995). Self-efficacy, attributions, and outcome expectancy mechanisms in reading and writing achievement: Grade-level and achievement-level differences. Journal of Educational Psychology, 87, 386-398. 
Shell, D. F., Murphy, C., \& Bruning, R. (1989). Self-efficacy and outcome expectancy mechanisms in reading and writing performance. Journal of Educational Psychology, 81, 91-100.

Skinner, E. A., \& Belmont, M. J. (1993). Motivation in the classroom: Reciprocal effects of teacher behavior and student engagement across the school year. Journal of Educational Psychology, 85, 571-581.

Stipek, D., Salmon, J. M., Givvin, K. G., Kazemi, E., Saxe, G., \& MacGyvers, V. L. (1998). The value (and convergence) of practices suggested by.motivation research and promoted by mathematics education reformers. Journal for Research in Mathematics Education, 29, 465-488.

Straub, R. (1996). The concept of control in teacher response: Defining the varieties of "directive" and "facilitative" commentary. College Composition and Communication, 47, 223-251.

Straub, R. (1997). Students' reactions to teacher comments: An exploratory study. Research in the Teaching of English, 31, 91-119.

Turner, J. C. (1995). The influence of classroom contexts on young children's motivation for literacy. Reading Research Quarterly, 30, 410-441.

Van Der Leeden, R., \& Busing, F. M. T. A. (1994). First interaction versus IGLS/RIGLS estimates in two-level models: A Monte Carlo study with ML3. Preprint PRM 94-03, Psychometrics and Research Methodology, Leiden, The Netherlands.

Walker, B. J. (2003). The cultivation of student self-efficacy in reading and writing. Reading and Writing Quarterly; Overcoming Learning Difficulties, 19, 173-187.

Weiner, B. (1979). A theory of motivation for some classroom experiences. Journal of Educational Psychology, 7I, 3-25.

Weiner, B. (1986). An attributional analysis of achievement motivation. New York: Springer Verlag.

Wentzel, K. R. (1999). Social-motivational processes and interpersonal relationships: Implications for understanding motivation at school. Journal of Educational Psychology, 91, 76-97.

Wong, B. (1996). Assessment and instruction of writing skills. In B. Wong (Ed.), The ABCs of learning disabilities (pp. 195-215). San Diego, CA: Academic Press.

Zuckerman, M., Porac, J., Lathin, D., Smith, R., \& Deci, E. L. (1978). On the importance of self-determination for intrinsically-motivated behavior. Personality and Social Psychology Bulletin, 4, 443-446.

\section{APPENDIX}

\section{Writing Lesson Motivational and Instructional Inventory}

How much do you agree that the following statements accurately describe the practices of your teacher in the writing lesson?

\section{Challenge}

1. Our teacher started with the easy concepts and progressively guided us through the difficult ones when teaching us how to write this essay.

2. Our teacher gave us writing assignments at the right level, neither too difficult nor too easy.

3. Our teacher, noting our failure to comprehend a subject, tried alternative teaching approaches until we understood.

\section{Real life significance}

1. Our teacher pointed out the relation between this genre of writing and our everyday life.

2. Our teacher pointed out the advantages of learning this genre of writing.

3. Our teacher helped us to understand that learning this genre of writing is not just for meeting course requirements but also for practical use. 


\section{APPENDIX-Continued}

Curiosity

1. Our teacher aroused our curiosity and interest before teaching us how to write this essay.

2. Our teacher raised some difficult questions in discussion and asked us to think them over.

3. Our teacher encouraged us to sort out the content of the essay on our own and did not provide a model answer.

\section{Autonomy}

1. Our teacher let us write the essay freely with our own ideas.

2. Our teacher allowed us freedom to choose between two tourist attractions for our writing.

3. Our teacher encouraged us to write this essay with our favorite approach.

\section{Recognition}

1. Our teacher praised not only the most successful students but also those who tried hard.

2. Our teacher encouraged us to make self-improvements and showed us that we did not need to win over others.

3. Our teacher gave recognition to students who had made progress despite the fact that they were not the best.

\section{Evaluation}

1. Our teacher pointed out those areas that needed improvement when marking my essay.

2. Our teacher made comments or suggestions when marking my essay, rather than merely giving the grade.

3. Our teacher evaluated our achievement by how well we had written rather than how we compared with other students.

Note. Measured with a 6-point Likert like scale: 1 (strongly disagree) to 6 (strongly agree). 


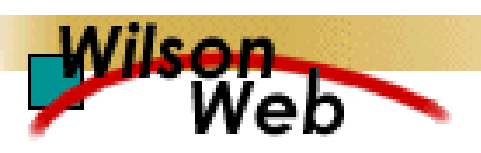

\section{COPYRIGHT INFORMATION}

TITLE: The Roles of Instructional Practices and Motivation in Writing Performance

SOURCE: J Exp Educ 75 no2 Wint 2007

WN: 0734902376009

The magazine publisher is the copyright holder of this article and it is reproduced with permission. Further reproduction of this article in violation of the copyright is prohibited. To contact the publisher: http://www.heldref.org/

Copyright 1982-2007 The H.W. Wilson Company. All rights reserved. 